\title{
Characterization of pilot-scale dilute acid pretreatment performance using deacetylated corn stover
}

\author{
Joseph Shekiro III*, Erik M Kuhn, Nicholas J Nagle, Melvin P Tucker, Richard T Elander and Daniel J Schell
}

\begin{abstract}
Background: Dilute acid pretreatment is a promising process technology for the deconstruction of low-lignin lignocellulosic biomass, capable of producing high yields of hemicellulosic sugars and enhancing enzymatic yields of glucose as part of a biomass-to-biofuels process. However, while it has been extensively studied, most work has historically been conducted at relatively high acid concentrations of 1 - $4 \%$ (weight/weight). Reducing the effective acid loading in pretreatment has the potential to reduce chemical costs both for pretreatment and subsequent neutralization. Additionally, if acid loadings are sufficiently low, capital requirements associated with reactor construction may be significantly reduced due to the relaxation of requirements for exotic alloys. Despite these benefits, past efforts have had difficulty obtaining high process yields at low acid loadings without supplementation of additional unit operations, such as mechanical refining.

Results: Recently, we optimized the dilute acid pretreatment of deacetylated corn stover at low acid loadings in a 1-ton per day horizontal pretreatment reactor. This effort included more than 25 pilot-scale pretreatment experiments executed at reactor temperatures ranging from $150-170^{\circ} \mathrm{C}$, residence times of $10-20$ minutes and hydrolyzer sulfuric acid concentrations between $0.15-0.30 \%$ (weight/weight). In addition to characterizing the process yields achieved across the reaction space, the optimization identified a pretreatment reaction condition that achieved total xylose yields from pretreatment of $73.5 \% \pm 1.5 \%$ with greater than $97 \%$ xylan component balance closure across a series of five runs at the same condition. Feedstock reactivity at this reaction condition after bench-scale high solids enzymatic hydrolysis was $77 \%$, prior to the inclusion of any additional conversion that may occur during subsequent fermentation.

Conclusions: This study effectively characterized a range of pretreatment reaction conditions using deacetylated corn stover at low acid loadings and identified an optimum reaction condition was selected and used in a series of integrated pilot scale cellulosic ethanol production campaigns. Additionally, several issues exist to be considered in future pretreatment experiments in continuous reactor systems, including the formation of char within the reactor, as well as practical issues with feeding herbaceous feedstock into pressurized systems.
\end{abstract}

Keywords: Deacetylated corn stover, Lignocellulosic pretreatment, Dilute acid, Xylose, Pilot

\section{Background}

Conversion of lignocellulosic biomass to fuels and chemicals continues to be a focus of worldwide research. While there are many different conversion pathways for producing biofuels, the biochemical conversion of biomass to ethanol is an area of keen focus. This pathway generally involves the hydrolysis of the polysaccharide

\footnotetext{
* Correspondence: joseph.shekiro@nrel.gov

National Bioenergy Center, National Renewable Energy Laboratory, 617 Cole Blvd, 80401 Golden, CO, USA
}

fraction of biomass to produce sugars followed by fermentation of these sugars to ethanol. Typically, a pretreatment process is employed that alters the biomass physical structure and chemical composition making the residual polysaccharides more susceptible to conversion to monomeric sugars by enzymatic hydrolysis. Pretreatment with dilute sulfuric acid also hydrolyzes hemicellulose to monomeric and oligomeric sugars. The primary goal when optimizing pretreatment performance is to identify operating conditions that maximize production of sugars from all available polysaccharides by varying 
parameters such as temperature, reaction time, and catalyst concentration. As such, most pretreatment researchers now report sugar yields from enzymatic hydrolysis of the pretreated solids as a key metric for determining optimum pretreatment conditions.

Recent reviews of pretreatment technologies are available from various authors, and an entire issue of the journal, Bioresource Technology, is devoted to the evaluation of different pretreatment technologies on the same biomass feedstock [1-4]. These results are summarized in a later publication [5]. The introductory article to the Bioresource Technology issue, as well as the review paper cited above, describe the outcomes of an effective pretreatment process [6]. For example, a pretreatment process should increase the effective surface area, decrease cellulose crystallinity, and increase pore size of the pretreated biomass. These changes improve enzymatic digestibility of the hemicellulose and cellulose remaining in the solids. Effective pretreatment techniques have been developed using acids, alkalis, hot water, steam explosion, oxidizers, ammonia, solvents, and ionic liquids. Many approaches rely on combined physical and chemical modifications to achieve good biomass pretreatment. Once optimized, most pretreatment processes are able to produce solids with good enzymatic digestibility, as noted by Elander et al. [5].

Many pretreatment studies are performed in small, batch-type reactors. While these reactors are sufficient for the characterizing pretreatment performance across a wide range of operating conditions, the optimum conditions found in small batch reactors do not translate well to pilot-scale reactors due to differences in heat and mass transfer characteristics. There are also physical modifications to the biomass that occur when it is fed into continuous, high-pressure reactors. The impact of these physical modifications of the biomass, including particle size reduction, on pretreatment performance is not well understood. For example, biomass is fed to many continuous pilot-scale reactors by a pressurized screw feeder, also known as a plug screw feeder. This device imparts high levels of compression and shear forces on the biomass, and is generally believed to modify the particle size distribution and other structural characteristics of the feedstock, but it is not known what impact these modifications have on pretreatment performance. Nevertheless, pilot-scale reactors likely produce pretreated materials similar to those produced in commercial-sized reactors, so evaluating downstream performance on these materials is vital to advancing process understanding.

In this work, we employed a newly constructed 20 to 40 dry $\mathrm{kg} / \mathrm{h}$ continuous pilot-scale pretreatment reactor system to pretreat biomass using dilute sulfuric acid. The system consists of a pressurized screw feeder that feeds biomass into a pressurized horizontal-tube reactor containing a series of screw augers for conveying the biomass and controlling residence time. Pretreated biomass is discharged through two full-port ball valves into a live-bottom flash tank. There are similarities to the National Renewable Energy Laboratory's (NREL's) older pilot-scale pretreatment system, but there are also significant differences, including lower electrical power requirements, horizontal reactor orientation instead of vertical, and a more effective discharge system [7]. This new reactor system was designed to be highly versatile, capable of pretreatment using acid or base chemistry and an array of biomass feedstocks. The reactor comprises several horizontal tubes, which can be reconfigured to achieve residence times between 2 minutes and 2 hours. In general, horizontal reactors are believed to offer improved residence time control over vertical reactor systems. However, vertical reactor systems are simpler and less expensive, both of which are advantages at larger scales [8].

Several researchers throughout the world have recently reported work in continuous pilot-scale pretreatment systems. Horizontal-tube reactors are currently being used in Italy, Denmark, Canada, and Taiwan for hydrothermal or acidic pretreatment of various biomass types at feed capacities ranging from 100 to $200 \mathrm{dry} \mathrm{kg} / \mathrm{h}$ [9-13]. Commercial companies are operating other pilotscale pretreatment systems throughout the world, but equipment details and performance results on these systems are not readily available [14].

The goal of this work was to assess performance of dilute sulfuric acid pretreatment of deacetylated corn stover in our new continuous pilot-scale pretreatment reactor at various operating conditions. The intent was to identify the best pretreatment operating conditions using low acid concentrations, less than $0.5 \%(\mathrm{w} / \mathrm{w})$ sulfuric acid concentration at reaction conditions, prior to executing a series of integrated pilot-scale campaigns for the production of ethanol. The feedstock for this work was deacetylated corn stover produced by treating raw corn stover with dilute sodium hydroxide prior to pretreatment. The work of Chen et al. demonstrated that dilute acid pretreatment of deacetylated corn stover produced higher monomeric xylose yields and improved cellulose digestibility of the pretreated solids compared to corn stover that was not deacetylated [15]. In the current study, performance was characterized by measuring pretreatment conversion yields and enzymatic cellulose digestibility of the pretreated solids.

\section{Results and discussion}

\section{Characterization of pretreatment performance}

To evaluate performance across a wide range of pretreatment severities, a series of 25 runs were performed 
in the pilot-scale pretreatment reactor at various operating conditions using a single lot of deacetylated corn stover. The operating conditions spanned pretreatment temperatures of 150 to $170^{\circ} \mathrm{C}$ and residence times of 10 to 20 minutes with sulfuric acid concentrations of 0.14 to $0.30 \%(\mathrm{w} / \mathrm{w})$ in the reactor. The residence time was estimated based on screw rotational speed and may not be the true residence time. The pretreated corn stover (PCS) at 27 to $35 \%(\mathrm{w} / \mathrm{w})$ total solids (TS) contained liquid phase monomeric xylose and glucose concentrations ranging from 36.7 to $94.1 \mathrm{~g} / \mathrm{L}$ and 0.5 to $13.7 \mathrm{~g} / \mathrm{L}$, respectively, depending on pretreatment severity. Oligomeric xylose and glucose concentrations ranged from 4.9 to $20 \mathrm{~g} / \mathrm{L}$ and 0.0 to $6.1 \mathrm{~g} / \mathrm{L}$, respectively. In singlestage dilute acid pretreatment, optimized for the production of monomeric and/or oligomeric xylose, the cellulose fraction of the biomass remains generally intact, with conversion of cellulose to glucose of up to $6 \%$ [16]. In this study, the total glucose (monomeric and oligomeric) yield in pretreatment was between 3.5 and $6.1 \%$ of the glucan present in the original corn stover. Complete concentration and yield data can be found in Additional file 1.

Mass balance closure results were calculated in several ways to assess process performance and data validity. Gravimetric mass closure was calculated by measuring mass of TS fed to the pretreatment reactor and accounting for all mass in the process effluents as either insoluble or dissolved solids in the PCS, or as organic compounds present in the flash or reactor vent vaporstreams. The calculation procedure is available in the methods section of this manuscript. Gravimetric mass balance closure for each run ranged from 100 to $102 \%$, indicating good tracking of mass entering and exiting the system Additionally, total and component (e.g. glucan, xylan) carbon mass balances around the pretreatment reactor system were performed as discussed in the methods section. Total carbon balance closure ranged from 95 to $102 \%$, with no discernible trend within the range of pretreatment severities tested. The good overall mass closure results suggest the accurate measurements of mass flow rates were made and that any componentlevel mass balance closure discrepancies may be attributed to analytical error and lack of quantification of specific compounds.

Component carbon mass balances for glucan and xylan ranged from 95 to $107 \%$ and 92 to $100 \%$, respectively. Xylan balance closures were observed to decrease beyond a combined severity of 1.25 as shown in Figure 1. This may be attributed to degradation of furfural to compounds that were not directly quantified. Conversely, these compounds are likely to be detected as lignin, as soluble sugars and other extractives react to form solids, which interfere with common insoluble lignin measurement techniques $[17,18]$. The mass balance closures for each individual experiment are included in Additional file 1.

The yields of compounds derived from xylan hydrolysis are depicted in Figure 1 plotted by combined severity. Combined severity $\left(\log \mathrm{R}_{0}\right)$ is an expression of pretreatment intensity as a function of reaction time ( $t$, minutes), temperature $\left(\mathrm{T},{ }^{\circ} \mathrm{C}\right)$ and $\mathrm{pH}$, and is defined as [19]:

$$
\log R_{0}=\log \left(t \times e^{(T-100)} / 14.75\right)-\mathrm{pH}
$$

Monomeric xylose yields increased from a combined severity of 0.56 to approximately 1.00 to 1.15 , where it reached a broad peak of approximately $68 \%$. The limited amount of data beyond a combined severity of 1.3 suggest monomeric xylose yields were beginning to decrease. The proportion of original xylan remaining in the insoluble solids decreased linearly within the range of test conditions from approximately $40 \%$ to just over $10 \%$ at the highest severity condition tested. Furfural yields increased linearly from $2.5 \%$ to about $6 \%$ between combined severities of 0.56 and 1.25 , with a sharper increase after a combined severity of 1.25 , reaching $12.6 \%$ at a combined severity of 1.34 . As expected, the yield of xylo-oligosaccharides fell with increasing severity, because higher pretreatment severity converts more oligomers to monomers.

Several studies exploring pilot-scale dilute acid pretreatment of corn stover found optimum monomeric xylose yields at combined severities of 1.2 to 1.6 , with corresponding monomeric xylose yields of approximately $70 \%$ and total xylose yields of up to $80 \%[7,16,20]$. However, because different researchers employ different equipment and methodologies, a comparison of our results to other studies can be difficult. For example, the actual residence time in pilot-scale continuous reactors may be different to the theoretical calculation because of back-mixing and non-ideal flow. Our preliminary work measuring the residence time distribution in the reactor used in this study is suggesting the actual residence time may as much 50 to $100 \%$ greater than the calculated value (data not shown). Thus, the true combined severity of experiments conducted in this study may be 10 to $25 \%$ greater than the values presented here.

To assess process variability, five runs were executed at pretreatment conditions of 10 minutes, $160^{\circ} \mathrm{C}$, and $0.26 \%(\mathrm{w} / \mathrm{w})$ sulfuric acid in the reactor. The average and standard deviation of the TS content of the PCS for these runs was $30.9 \% \pm 3.3 \%$. Average monomeric and oligomer xylose concentrations were $83.6 \pm 8.1 \mathrm{~g} / \mathrm{L}$ and $7.6 \pm 1.3 \mathrm{~g} / \mathrm{L}$, respectively. Average component yields for the various xylan derived fractions were $67.4 \% \pm 1.7 \%$ for monomeric xylose, $6.1 \% \pm 0.4 \%$ for oligomeric xylose, $5.3 \% \pm 0.4 \%$ for furfural, and $18.5 \% \pm 0.6 \%$ for unreacted 


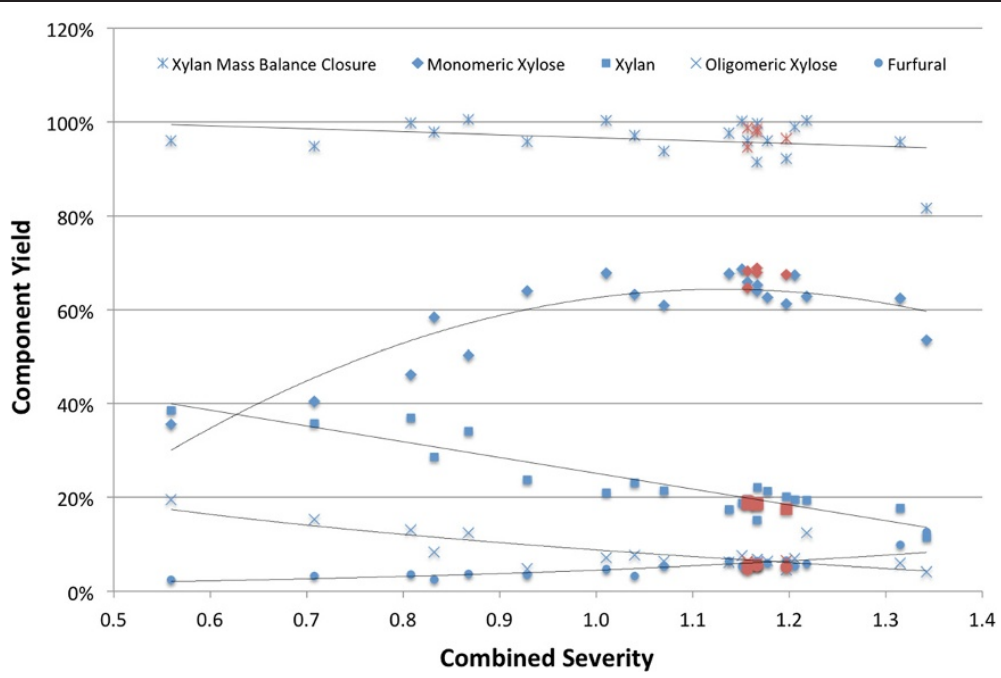

Figure 1 Xylan derived component yields from dilute acid hydrolysis of deacetylated corn stover as a function of pretreatment severity. Red points represent replicated runs conducted at $160^{\circ} \mathrm{C}, 10$ minutes with $0.34 \%(\mathrm{w} / \mathrm{w}) \mathrm{H}_{2} \mathrm{SO}_{4}$ in the pretreatment reactor. Trends are shown by regressed lines.

xylan. The average xylan mass balance closure was $97.3 \% \pm 1.7 \%$. Potential sources of variation include cyclical deviation in stream flows (for example, steam, corn stover, water) caused by feedback control loops and corresponding changes in operating conditions as well as variability in the moisture content of corn stover. All of these factors lead to slight differences in reaction $\mathrm{pH}$ and temperature and ultimately differing pretreatment efficacies. Reaction $\mathrm{pH}$, combined severity and effective acid concentration for each pretreatment experiment are available in Additional file 1.

Pretreated biomass exits the pretreatment reactor through a pair of alternating full-port ball valves into an atmospheric pressure flash tank separating into a flash vapor stream and a PCS stream. The flash evaporation process releases volatile compounds from the PCS slurry and the most easily measured components are furfural and acetic acid. The concentrations of these components in the PCS liquor fraction and furfural concentration in the condensed flash vapor are plotted as functions of combined severity in Figure 2. Concentrations of furfural in the flash vapor and PCS liquor fraction increase with increasing furfural production associated with increasing pretreatment severity (see Figure 1). Approximately 50 to $60 \%$ of the furfural produced is recovered in the flash vapor stream, reaching concentrations in this stream near $30 \mathrm{~g} / \mathrm{L}$ at the highest pretreatment severity. The more important consideration is furfural concentration in the PCS liquor, as furfural is a potent fermentation inhibitor $[17,18]$. Below a combined severity of 1.25 the furfural concentrations were less than $1.5 \mathrm{~g} / \mathrm{L}$, a concentration tolerated by many microorganisms. At the highest pretreatment severity, the furfural concentration was near $4.0 \mathrm{~g} / \mathrm{L}$, which is inhibitory to many microorganisms.

Because the deacetylation process extracts approximately $80 \%$ of acetate from the corn stover, the acetic acid concentrations in the liquor are independent of pretreatment severity, a finding also observed by Chen et al. [21]. Consequently, acetic acid concentrations were only 1.5 to $2.5 \mathrm{~g} / \mathrm{L}$, drastically lower than the 8 to $12 \mathrm{~g} / \mathrm{L}$ observed in the literature for high-solids dilute acid pretreatments [22,23]. Only 5 to $10 \%$ of acetic acid produced during pretreatment was recovered in the flash vent stream.

\section{Feedstock reactivity}

As the primary carbohydrate in corn stover is glucan, xylan-to-xylose yield in isolation is not an effective metric for assessing pretreatment performance. Rather, the feedstock reactivity, a relative measure of the total sugar yield was calculated from the total xylan-to-xylose yield and the yield of monomeric glucose from enzymatic cellulose hydrolysis of each PCS sample. The calculation is described in the methods section. Calculated feedstock reactivity for each of the experiments is shown in Figure 3.

The yield of monomeric glucose from cellulose during enzymatic hydrolysis slowly increased with increasing pretreatment combined severity (results not shown but are available in Additional file 1). This behavior is typically ascribed to increasing accessibility of the cellulose to enzymatic attack as a greater fraction of the hemicellulose is solubilized with increasing pretreatment severity $[7,16]$. However, within the range of pretreatment severities tested, feedstock reactivity appeared to reach a 

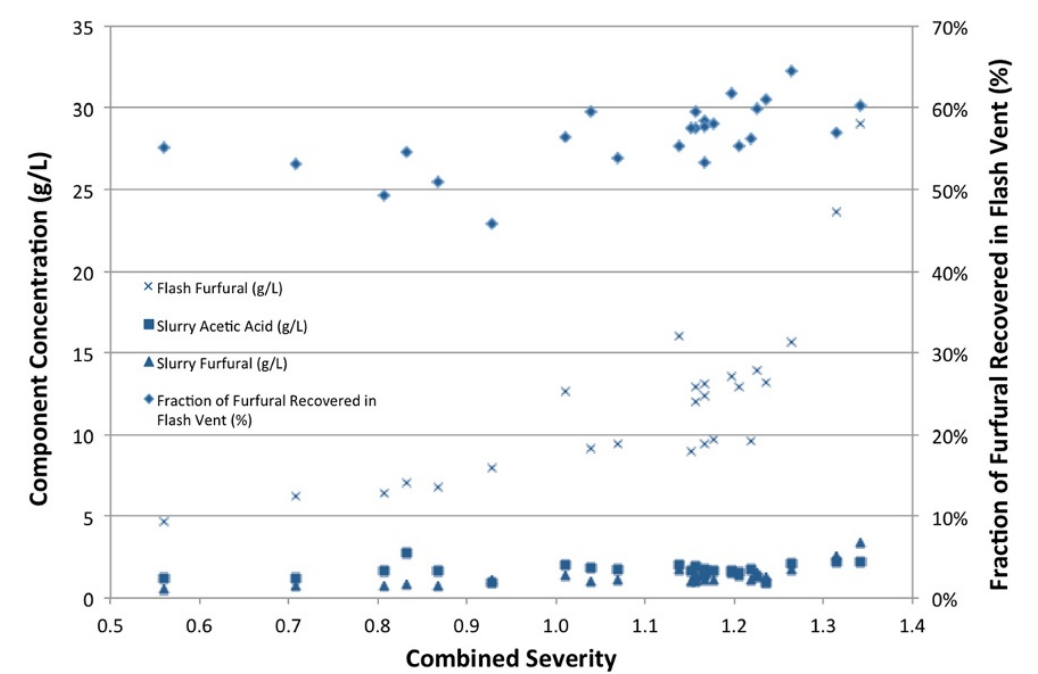

Figure 2 Pretreated corn stover liquor acetic acid and furfural concentrations and furfural concentration in the flash vapor, along with fraction of the total furfural recovered in the flash vapor.

broad maximum of 70 to $80 \%$ at the higher combined severities. Even though xylose yields were decreasing after a combined severity of 1.15 , increasing cellulose digestibility was causing the feedstock reactivity to remain relatively constant at combined severities greater than 1.1. Previous work using dilute-acid pretreated slurry produced at reduced acid loadings in pilot reactor systems achieved lower enzymatic cellulose to glucose conversions (60 to $70 \%$ ) than the present work (70 to $80 \%$ ) [24]. These experiments achieved significantly lower xylanto-xylose yields in pretreatment.
While the conversion of xylo-oligomers and insoluble xylan to xylose during enzymatic hydrolysis was not evaluated in these experiments, previous studies have shown that a significant proportion of the oligomers can be converted enzymatically to xylose [25-27]. This finding was confirmed in the subsequent integrated pilot-scale ethanol production campaigns previously mentioned (data not shown). Based on these results, the pretreatment condition selected for the pilot-scale campaigns was $160^{\circ} \mathrm{C}, 10$ minutes, and a reactor acid concentration of $0.34 \%$. This condition balanced the need to preserve xylan

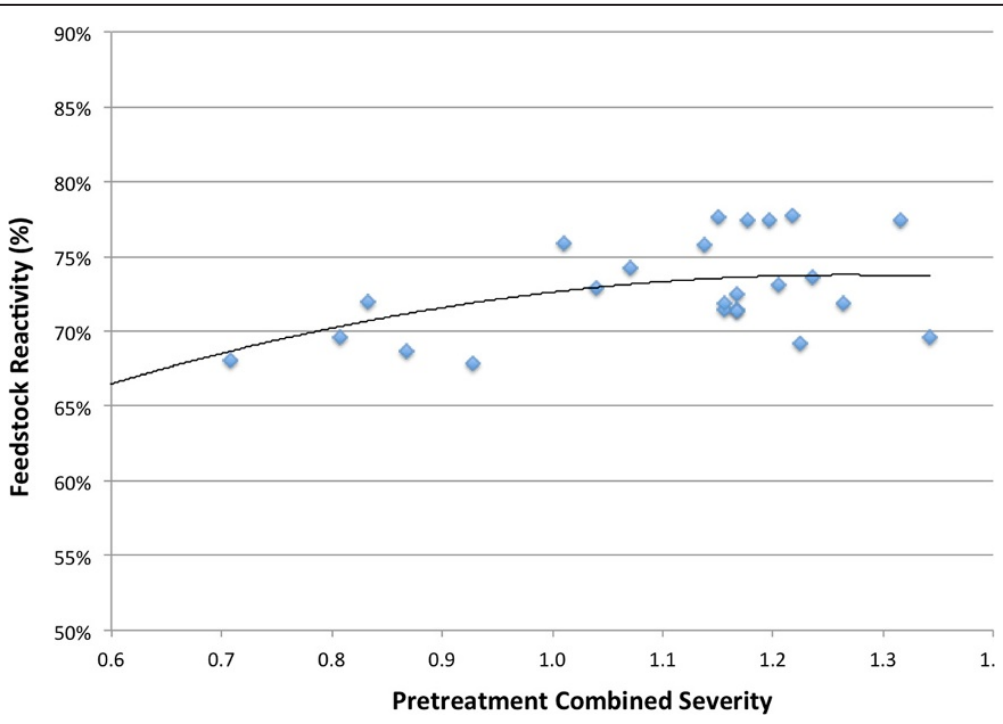

Figure 3 Feedstock reactivity (based on total monomeric and oligomeric xylose as defined in the methods section) as a function of combined severity. 
for potential subsequent conversion, while also maximizing xylose yield from pretreatment and glucose yield from enzymatic hydrolysis.

\section{Operational observations}

During commissioning the pretreatment reactor, two issues arose that are worthy of discussion. The first issue was intermittent difficulty feeding deacetylated corn stover into the reactor using the plug screw feeder. It was determined though trial and error that 1.3 to $1.9 \mathrm{~cm}$ ( 0.50 to 0.75 in) hammer-milled corn stover had a higher quantity of fine particles and lower cohesive strength than knife-milled corn stover. Consequently, we believe that as the corn stover is driven forward and compressed by the plug screw feeder, the material within the rotating flights separates from the fraction packed within the anti-rotation device, causing the forward movement of corn stover to slow or halt. This separation, commonly described as plug shearing, results in cessation of feeding and is manifested as a discrete decrease in the electrical current required by the plug screw feeder motor and an accumulation of corn stover in the inlet zone of the plug screw feeder. If not quickly addressed, a sheared plug can result in rapid pressure release from the reactor back through the plug screw feeder. Figures of several anti-rotation mechanisms are not reproduced here, but are available in many current patents [28-30]. It should be noted that this problem is not seen during feeding of either hammer-milled or knife-milled untreated (raw) corn stover.

Additionally, after approximately 200 hours of operation, significant accumulation of a black, coke-like substance was observed on the walls of the reactor and within the flights of the augers. This substance was also found within the pressurized but non-jacketed discharge sections of the reactor. The material, shown in Figure 4, was generally brittle, but insoluble in acid or base solutions even at elevated temperatures. To clean the reactor it was completely disassembled and surfaces were scraped to remove as much of the material as possible. An elemental analysis of the material found it to be approximately $66 \%$ carbon, $27 \%$ oxygen, $5 \%$ hydrogen and $1 \%$ nitrogen by mass, with a $\mathrm{C}: \mathrm{O}$ ratio of roughly $2.2: 1$. This material was significantly enriched in carbon content relative to native corn stover, which has a $\mathrm{C}: \mathrm{O}$ ratio of approximately 1:1. The composition is consistent the condensation products that can form when furans, such as furfural, react with monomeric and oligomeric sugars to form insoluble humins [31].

\section{Conclusions}

The intent of this work was to understand pretreatment of deacetylated corn stover at low acid concentrations in pilot-scale reactors. This is the first known work testing pretreatment of deacetylated biomass in pilot-scale reactors for fuel production. Low acid concentrations are desirable because they may eliminate the need for exotic materials of construction for pretreatment reactors. For example, lower-cost stainless steels could be used in place of expensive Hastelloy. Additionally, a lesser quantity of caustic reagent is needed for neutralizing these slurries prior to enzymatic hydrolysis, which reduces chemical costs and perhaps downstream operating cost, particularly for wastewater treatment.

Commissioning the newly installed horizontal reactor system identified several operational challenges that should be addressed in similar reactor designs, or considered in ongoing pretreatment operations. First, the structural characteristics of a feedstock must be evaluated in addition to its composition and recalcitrance. It is clear that some feedstocks, or methods of preparing feedstock create a non-ideal substrate for pressurized (plug) screw feeder operation. This work highlighted the need for maintenance and cleaning programs to prevent or minimize the deposition of charred solids on reactor surfaces.

Deacetylated corn stover was successfully pretreated and an optimum pretreatment condition of $160^{\circ} \mathrm{C}, 10 \mathrm{mi}-$ nutes, and $0.26 \% \mathrm{H}_{2} \mathrm{SO}_{4}$ (combined severity of 1.15 to 1.20) was identified for future work. This condition balanced the need to minimize the formation of degradation products, maximize sugar yields, and reduce acid consumption. Pretreated slurries produced in this severity range achieved total xylose concentrations of over $100 \mathrm{~g} / \mathrm{L}$ at $30 \% \mathrm{TS}$ and feedstock reactivity (an estimate of total sugar yield) up to $77 \%$. Furfural and acetic acid concentrations ranged between 1.3 to $1.5 \mathrm{~g} / \mathrm{L}$ and 1.0 to $1.9 \mathrm{~g} / \mathrm{L}$ respectively, and should be well-tolerated by most fermentative microorganisms.

Given that the range of operating conditions explored in this study is still somewhat limited, opportunities still exist for further performance improvements. However, integrated pretreatment, enzymatic hydrolysis and fermentation performance data are needed to optimize overall process performance.

\section{Methods}

\section{Feedstock}

The corn stover was harvested in Emmetsburg, IA, USA in October 2010 and shipped to Idaho National Laboratory (INL, Idaho Falls, ID, USA). There it was processed using the pilot-scale feedstock-handling unit operated by INL as described by Yancey et al. and hammer-milled to pass through a $1.9-\mathrm{cm}-(0.75$-in)-round rejection screen [32]. The composition of the raw feedstock is described in Table 1.

\section{Feedstock deacetylation and acid impregnation}

The overall process flow for this work is shown in Figure 5. Corn stover deacetylation and sulfuric acid 

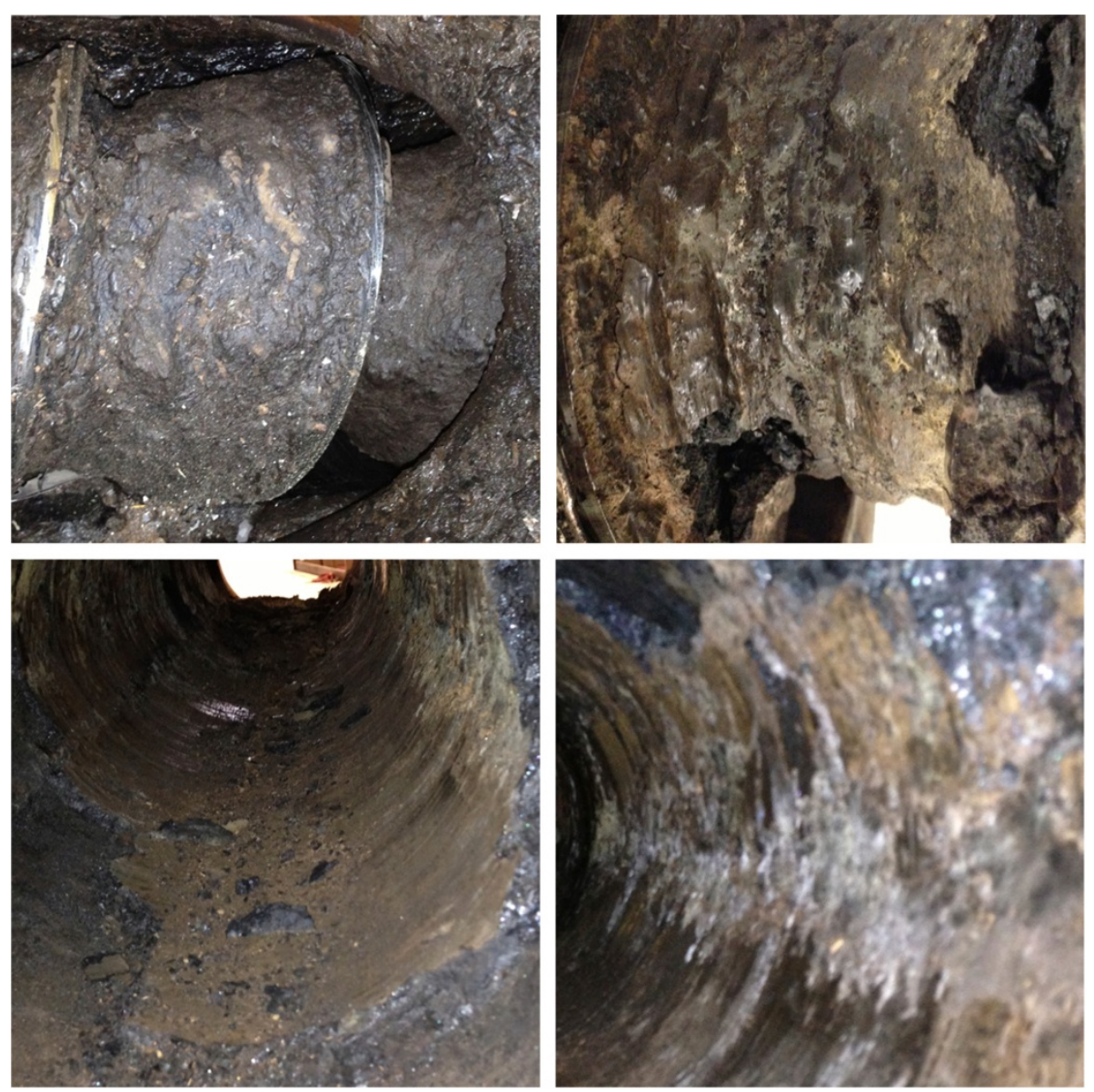

Figure 4 Images of carbonaceous deposits observed on reactor augers and walls.

impregnation was performed in a 1,900-L horizontal jacketed vessel (American Process Systems, Gurnee, IL, USA) agitated with paddles suspended from a central shaft. Dry corn stover (100 to 120 dry $\mathrm{kg}$ ) was added to the tank along with a dilute sodium hydroxide solution $(0.4 \% \mathrm{w} / \mathrm{w})$ to achieve a TS loading of $8 \%(\mathrm{w} / \mathrm{w})$. The slurry was continuously mixed, heated to $80^{\circ} \mathrm{C}$ and held for 2 hours. The free-liquid fraction was subsequently allowed to drain overnight. The solids were then re-suspended in water for one hour at $10 \%$ TS and allowed to drain once again. A dilute sulfuric acid solution $(0.5 \%$ or $0.8 \% \mathrm{w} / \mathrm{w})$ was then added to the drained solids to achieve a TS loading of $8 \%(\mathrm{w} / \mathrm{w})$. After thoroughly mixing the acid-impregnated solids at room temperature for 2 hours, the slurry was pumped to a continuous screw press (Vincent Corp. Model CP10, Tampa, FL, USA) to dewater the solids to 45 to $50 \%(\mathrm{w} / \mathrm{w})$ TS. The deacetylated and acid-impregnated corn stover (DAICS) solids were collected in drums and stored

Table 1 Composition of raw corn stover and alkaline extracted and acid impregnated corn stover

\begin{tabular}{|c|c|c|c|c|c|c|c|c|c|c|c|}
\hline & $\begin{array}{l}\text { Sucrose } \\
(\%)\end{array}$ & $\begin{array}{l}\text { Glucan } \\
(\%)\end{array}$ & $\begin{array}{l}\text { Xylan } \\
(\%)\end{array}$ & $\begin{array}{l}\text { Galactan } \\
(\%)\end{array}$ & $\begin{array}{l}\text { Arabinan } \\
\text { (\%) }\end{array}$ & $\begin{array}{l}\text { Lignin } \\
(\%)\end{array}$ & $\begin{array}{l}\text { Protein } \\
(\%)\end{array}$ & $\begin{array}{l}\text { Ash } \\
\text { (\%) }\end{array}$ & $\begin{array}{l}\text { Acetyl } \\
(\%)\end{array}$ & $\begin{array}{l}\text { Water/ethanol- } \\
\text { extractible others (\%) }\end{array}$ & $\begin{array}{l}\text { Total mass } \\
\text { closure }(\%)\end{array}$ \\
\hline $\begin{array}{l}\text { Raw corn } \\
\text { stover }\end{array}$ & $0.2 \pm 0.1$ & $35.1 \pm 0.6$ & $23.3 \pm 1.6$ & $1.9 \pm 0.1$ & $3.5 \pm 0.2$ & $15.1 \pm 0.3$ & $2.1 \pm 0.2$ & $8.5 \pm 0.4$ & $1.9 \pm 0.2$ & $5.8 \pm 1.5$ & $97.6 \pm 0.6$ \\
\hline $\begin{array}{l}\text { Deacetylated } \\
\text { corn stover }\end{array}$ & ND & $44.7 \pm 0.9$ & $25.3 \pm 0.7$ & $1.7 \pm 0.1$ & $3.7 \pm 0.2$ & $16.3 \pm 1.3$ & $0.2 \pm 0.4$ & $3.8 \pm 0.3$ & $0.3 \pm 0.2$ & ND & $96.0 \pm 0.8$ \\
\hline
\end{tabular}

Standard deviations calculated using duplicate analyses of six independent samples of raw corn stover and 21 independent samples of deacetylated and acid-impregnated corn stover. ND - None detected. 


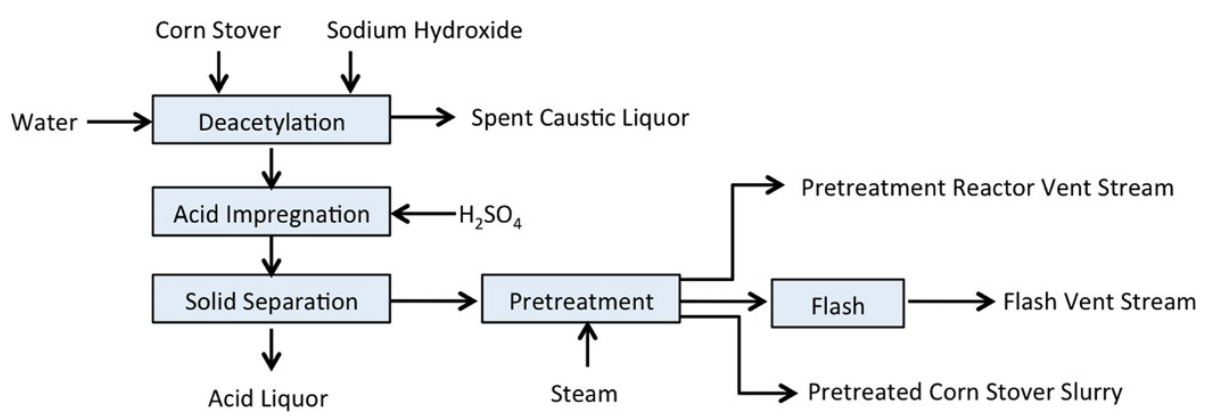

Figure 5 Block flow diagram of the deacetylation, impregnation and pretreatment processes.

at room temperature prior to use in pretreatment. Samples of DAICS were taken from each batch prepared as described above and the average composition of the 25 samples is shown in Table 1. However, yield calculations for each experiment were performed using the composition of the individual batch of DAICS used for that experiment.

\section{Pilot-scale pretreatment}

The horizontal pretreatment reactor (Mesto Inc., Norcross, GA, USA) was operated at temperatures of 150 to $170^{\circ} \mathrm{C}$ and residence times of 10 to 20 minutes. The residence time was calculated based on the screw speed, assuming no back-mixing of the solids. A full list of the pretreatment conditions used in this study is shown in Additional file 1. The pretreatment reactor was preheated using steam jackets for 1 hour and allowed to reach the desired temperature before adding DAICS into the reactor. DAICS was manually fed to an Acrison Inc. feeder (Moonachie, HJ, USA), which delivered feedstock at a constant volumetric rate to a weigh-belt (K-tron, Pitman, NJ, USA) configured to deliver a constant mass flow rate of biomass into the pretreatment system at 25 to $30 \mathrm{dry} \mathrm{kg} / \mathrm{h}$. After discharge from the weigh- belt, the DAICS was fed into the pressurized zone of the reactor by pressurized (plug) screw feeder and heated to the desired temperature by direct steam injection. DAICS was conveyed through the horizontal tubes by a screw auger with residence time controlled by the rotational speeds of the screw. The pretreated slurry was discharged into an atmospheric pressure flash tank through a pair of automated, air-actuated ball valves opening and closing in an alternating pattern so as to prevent rapid depressurization of the reactor.

Upon entering the flash tank, the hydrolyzate separates into a pretreated high-solids (approximately 30\% w/w) slurry stream (PCS), and a flash-tank vent stream. The flash-tank vent stream was condensed in a heat exchanger. The flash vapor flow-rate was determined from mass and energy balance calculations around the pretreatment process. Additionally, volatile compounds were removed from the pretreatment reactor by venting a small vapor stream (pretreatment reactor vent) from the high point of the reactor at a flow rate of $5 \mathrm{~kg} / \mathrm{h}$. The flow rate was measured by a coriolis flow meter (Emerson Controls (Micro Motion), Boulder, CO, USA). This stream was also condensed in a heat exchanger.

At each pretreatment operating condition, PCS was collected in a drum for a period of 20 minutes; samples of DAICS, PCS and condensates from both the flash and reactor vents were taken and stored at $4^{\circ} \mathrm{C}$ prior to compositional analysis. After all samples were collected, the pretreatment reactor set points were changed for the next experiment. Upon a change in reactor set point such as steam pressure, residence time, or feed rate, or other process disruption, at least two residence times were allowed to elapse after all flow rates reached steady state prior to the collection of any samples. Data such as stream flows and reactor conditions were collected in real time and recorded by a data acquisition and control system.

The gravimetric mass balance was calculated by dividing the sum of mass flow rates of solids recovered in each of the process effluent streams (PCS, reactor vent, flash vent) by the mass flow rate of dry corn stover fed to the reactor, as measured by the weigh-belt. The calculation was performed using mass flow rate measurements $(\dot{M}, \mathrm{~kg} / \mathrm{h})$, TS $(\% \mathrm{w} / \mathrm{w})$, densities $(\rho, \mathrm{kg} / \mathrm{L})$, and concentrations $(\mathrm{C}, \mathrm{g} / \mathrm{L})$ of various compounds in each stream, as shown in Equations 2 to 6:

$$
\begin{aligned}
& \dot{\mathrm{M}}_{\text {Feedstock }}=\dot{\mathrm{M}}_{\text {Feedstock }, \text { in }} \mathrm{x} \% \mathrm{TS}_{\text {Feedstock }} \\
& \dot{\mathrm{M}}_{\mathrm{PCS}}=\dot{\mathrm{M}}_{\text {PCS, Out }} \mathrm{x} \% \mathrm{TS}_{P C S} \\
& \dot{\mathrm{M}}_{\text {Reactor Vent }}=\frac{\dot{\mathrm{M}}_{\text {Reactor Vent }}}{\rho_{\text {Reactor Vent }}} \mathrm{x}\left(C_{\text {Furfural }}+C_{\text {Acetic Acid }}\right)
\end{aligned}
$$




$$
\dot{\mathrm{M}}_{\text {Flash Vent }}=\frac{\dot{\mathrm{M}}_{\text {Flash Vent }}}{\rho_{\text {Flash Vent }}} \mathrm{x}\left(C_{\text {Furfural }}+C_{\text {Acetic Acid }}\right)
$$

$$
\begin{aligned}
& \text { Gravimetric mass balance closure }(\%) \\
& =\frac{\dot{\mathrm{M}}_{\mathrm{PCS}}+\dot{\mathrm{M}}_{\text {Reactor Vent }}+\dot{\mathrm{M}}_{\text {Flash Vent }}}{\dot{M}_{\text {Feedstock }}}
\end{aligned}
$$

In addition to the gravimetric mass balance, process yields and component carbon mass balances were calculated by a carbon mass balance technique using a method previously described by Hatzis et al. [7,33]. For calculating xylan and glucan mass balances, it was assumed that all furfural was derived from only xylan, and that 5-hydroxy-methyl furfural (HMF) was only derived from sucrose.

\section{Cellulose digestibility assay}

Cellulose digestibility is defined as the percent of the cellulose in the PCS converted to monomeric glucose during enzymatic hydrolysis at the conditions discussed below. PCS was neutralized with $14 \%(\mathrm{w} / \mathrm{w})$ ammonium hydroxide at room temperature $\left(22^{\circ} \mathrm{C}\right)$ to approximately pH 5. Sufficient neutralized PCS, enzyme (Cellic CTec 2, Novozymes, Davis, CA, USA), and $50 \mathrm{mM}$ citrate buffer (pH 4.9) solution (total mass of $100 \mathrm{~g}$ ) was added to 250-mL capped bottles to achieve a $20 \%$ PCS TS loading. The enzyme loading was $40 \mathrm{mg}$ protein/g cellulose with the assumption that the cellulose content of each PCS sample was $50 \%(\mathrm{w} / \mathrm{w})$ on a dry basis. As the protein loading was quite high and the range of pretreatment severities fairly narrow, it was assumed that small differences in actual enzyme loading would not be detectable. The bottles were placed in a shaking incubator rotating at $150 \mathrm{rpm}$ and maintained at $48^{\circ} \mathrm{C}$. Enzymatic hydrolysis was performed for $96 \mathrm{~h}$. The difference between final and initial monomeric glucose concentration was used to calculate cellulose digestibility (monomeric glucose yield) according to the method described by Roche et al. [34]. Each analysis was performed in duplicate and average values are reported.

Using cellulose digestibility and the total (monomers and oligomers) xylose yield from pretreatment, a parameter called the feedstock reactivity (FR) was calculated as shown in Equation 9, where $X$ is the mass fraction of a given component. The parameter is a simplified representation of sugar produced by combined pretreatment and enzymatic hydrolysis and was used for making relative performance comparisons.

\section{Chemical analysis}

Sugar concentrations were measured by HPLC using an Agilent 1100 series HPLC (Santa Clara, CA, USA) with a Shodex SP0810 carbohydrate column (Shawa Denko K.K., Kawasaki, Japan) and a de-ashing guard cartridge (BioRad Laboratories, Hercules, CA, USA). The column temperature was $85^{\circ} \mathrm{C}$ and the mobile phase was ultrapure water at a flow rate of $0.6 \mathrm{~mL} /$ minute. Acetic acid, HMF, and furfural concentrations were measured by HPLC using a Phenomenex Rezex RFQ Fast Fruit H + organic acid column and Cation $\mathrm{H}+$ guard cartridge (BioRad Laboratories) at $55^{\circ} \mathrm{C}$. The mobile phase was dilute sulfuric acid $(0.01 \mathrm{~N})$ at a flow rate of $0.6 \mathrm{~mL} /$ minute. A refractive index detector was used for compound detection for both columns. Mixed component standards were periodically run with the HPLC samples to verify calibration accuracy. The density of liquid samples was measured using an Anton-Parr model DMA-500 density meter (Anton Parr USA, Inc., Ashland, VA, USA).

The composition of pretreated solids was determined using a two-stage acid digestion procedure [35]. Concentrations of total soluble sugars in pretreated liquor samples were determined using a mild dilute acid hydrolysis procedure and HPLC analysis [36]. Concentration of the oligomeric sugar was the difference between total and monomeric sugar concentration. Slurry TS concentrations were determined by drying samples at $45^{\circ} \mathrm{C}$ in a vacuum oven (0.6 bar) until repeated weight measurements were constant. Slurry insoluble solid concentrations were determined by a six-step washing and centrifugation procedure [7]. Triplicate measurements were performed on each sample.

The enzyme was desalted prior to measuring the protein content. Desalting was performed on a HiPrep 26/10 desalting column (GE Healthcare, Uppsala, Sweden) with a Sephadex G-25 column matrix using a 2-mL sample. The mobile phase was a $50 \mathrm{mM}$ Tris, $150 \mathrm{mM} \mathrm{NaCl} \mathrm{pH} 5$ buffer at a flow rate of $10 \mathrm{~mL} /$ minute. Protein concentration was measured using the Pierce BCA (BCA Protein Assay Kit, Pierce, IL, USA) assay following the manufacturer's protocols with bovine serum albumin as the protein standard. The measurement was performed in triplicate.

\section{Additional file}

Additional file 1: Supplemental data referred to within the manuscript, including specific component yields in pretreatment and enzymatic hydrolysis, pretreatment mass balance closure and reactor operational conditions.

$$
F R=\frac{\text { Yield of Glucose } e_{E H} \times X_{\text {Glucan,Feedstock }}+\text { Yield of Total Xylose } e_{P T} \times X_{X y l a n, F e e d s t o c k}}{X_{G l u c a n, F e e d s t o c k}+X_{X y l a n, F e e d s t o c k}}
$$




\section{Abbreviations}

DAICS: deacetylated and acid-impregnated corn stover; FR: feedstock reactivity; HMF: 5-hydroxy-methyl furfural; HPLC: high performance liquid chromatography; PCS: pretreated corn stover; TS: total solids.

\section{Competing interests}

The authors declare that they have no competing interests.

\section{Authors' contributions}

JS executed the pretreatment experiments, analyzed data, and prepared the manuscript along with DJS. JS, DJS, EMK, NJN, MPT, and RTE conceived the work and developed the experimental design. All authors read, revised and approved the final manuscript.

\section{Acknowledgements}

Pilot Plant operation support was provided by Xiaowen Chen, Joseph Farmer, Blake Galliford, Casey Gunther, Wesley Hjelm, Timothy Johnston, Jason Kerwood, Eric Nelson, and Nicholas Rinaldo. Analytical sample analysis was performed by Deborah Hyman, Darren Peterson, Michelle Reed, David Templeton, and Jeffery Wolfe. The cellulose digestibility assay was performed by Robert Nelson.

The US Department of Energy Bioenergy Technologies Office provided funding for this work.

Received: 13 November 2013 Accepted: 6 February 2014

Published: 18 February 2014

\section{References}

1. Agbor VB, Cicek N, Sparling R, Berlin A, Levin DB: Biomass pretreatment: fundamentals toward application. Biotechnol Adv 2011, 29:675-685.

2. Modenbach AA, Nokes SE: The use of high-solids loadings in biomass pretreatment-a review. Biotechnol Bioeng 2012, 109:1430-1442.

3. Zhao X, Zhang L, Liu D: Biomass recalcitrance. Part II: fundamentals of different pre-treatments to increase the enzymatic digestibility of lignocellulose. Biofuels Bioprod Biorefin 2012, 6:561-579.

4. Dale B: Coordinated Development of Leading Biomass Pretreatment Technologies. Bioresource technol. 2005, 96-18:1959-2032.

5. Elander RT, Dale BE, Holtzapple M, Ladisch MR, Lee YY, Mitchinson C, Saddler JN, Wyman CE: Summary of findings from the biomass refining consortium for applied fundamentals and innovation (CAFI): corn stover pretreatment. Cellulose 2009, 16:649-659.

6. Mosier N, Wyman C, Dale B, Elander R, Lee Y, Holtzapple M, Ladisch M: Features of promising technologies for pretreatment of lignocellulosic biomass. Bioresource Technol 2005, 96:673-686.

7. Schell DJ, Farmer J, Newman M, McMillan JD: Dilute-sulfuric acid pretreatment of corn stover in pilot-scale reactor - investigation of yields, kinetics, and enzymatic digestibilities of solids. Appl Biochem Biotechnol 2003, 105-108:69-85.

8. Elander R: Experimental pretreatment systems from laboratory to pilot scale. In Aqueous pretreatment of plant biomass for biological and chemical conversion to fuels and chemicals. Hoboken, NJ: John Wiley \& Sons, Ltd: Chichester CW; 2013:427-445

9. Chen W-H, Tsai C-C, Lin C-F, Tsai P-Y, Hwang W-S: Pilot-scale study on the acid-catalyzed steam explosion of rice straw using a continuous pretreatment system. Bioresource Technol 2013, 128:297-304

10. De Bari I, Viola E, Barisano D, Cardinale M, Nanna F, Zimbardi F, Cardinale G, Braccio G: Ethanol production at flask and pilot scale from concentrated slurries of steam-exploded aspen. Ind Eng Chem Res 2002, 41:1745-1753.

11. Fang $H$, Deng J, Zhang T: Dilute acid pretreatment of black spruce using continuous steam explosion system. Appl Biochem Biotechnol 2011, 163:547-557.

12. Larsen J, Petersen M $\varnothing$ : The IBUS process - lignocellulosic bioethanol close to a commercial reality. Chem Eng Technol 2008, 96:673-686.

13. Petersen $M \varnothing$, Larsen J, Thomsen MH: Optimization of hydrothermal pretreatment of wheat straw for production of bioethanol at low water consumption without addition of chemicals. Biomass Bioenerg 2009, 33:834-840.

14. Bacovsky D, Dallos M, Woergetter M: Status of 2nd generation biofuels demonstration facilities in June 2010. IEA Bioenergy Task 39: Commercializing 1st and 2nd generation liquid biofuels from biomass 2010, T39-P1b:1-126.

15. Chen X, Tao L, Shekiro J, Mohaghaghi A, Decker S, Wang W, Smith H, Park S, Himmel ME, Tucker M: Improved ethanol yield and reduced Minimum
Ethanol Selling Price (MESP) by modifying low severity dilute acid pretreatment with deacetylation and mechanical refining: 1) Experimental. Biotechnol Biofuels 2012, 5:60.

16. Lloyd TA, Wyman CE: Combined sugar yields for dilute sulfuric acid pretreatment of corn stover followed by enzymatic hydrolysis of the remaining solids. Bioresource Technol 2005, 96:1967-1977.

17. Katahira R, Sluiter JB, Schell DJ, Davis MF: Degradation of carbohydrates during dilute sulfuric acid pretreatment can interfere with lignin measurements in solid residues. J Agric Food Chem 2013, 61:3286-3292.

18. Sluiter JB, Ruiz RO, Scarlata CJ, Sluiter AD, Templeton DW: Compositional analysis of lignocellulosic feedstocks. 1. Review and description of methods. J Agric Food Chem 2010, 58:9043-9053.

19. Chum HL, Johnson DK, Black SK, Overend RP: Pretreatment catalyst effects and the combined severity parameter. Appl Biochem Biotechnol 1990, 24-5:1-14.

20. Esteghlalian A, Hashimoto AG, Fenske JJ, Penner MH: Modeling and optimization of the dilute-sulfuric-acid pretreatment of corn stover poplar and switchgrass. Bioresource Technol 1997, 59:129-136.

21. Chen X, Shekiro J, Elander R, Tucker M: Improved xylan hydrolysis of corn stover by deacetylation with high solids dilute acid pretreatment. Ind Eng Chem Res 2011, 51:70-76.

22. Ranatunga TD, Jervis J, Helm RF, McMillan JD, Wooley RJ: The effect of overliming on the toxicity of dilute acid pretreated lignocellulosics: the role of inorganics, uronic acids and ether-soluble organics. Enzyme Microb Technol 2000, 27:240-247.

23. Ranatunga TD, Jervis J, Helm RF, McMillan JD, Hatzis C: Identification of inhibitory components toxic toward Zymomonas mobilis CP4 (pZB5) xylose fermentation. Appl Biochem Biotechnol 1997, 67:185-198.

24. Weiss N, Farmer J, Schell DJ: Impact of corn stover composition on hemicellulose conversion during dilute acid pretreatment and enzymatic cellulose digestibility of the pretreated solids. Bioresource Technol 2010, 101:674-678.

25. Agger J, Vikso-Nielsen A, Meyer AS: Enzymatic xylose release from pretreated corn bran arabinoxylan: Differential effects of deacetylation and deferuloylation on insoluble and soluble substrate fractions. J Agric Food Chem 2010, 58:6141-6148.

26. Sorensen HR, Pedersen $\mathrm{S}$, Jorgensen $\mathrm{CT}$, Meyer AS: Enzymatic hydrolysis of wheat arabinoxylan by a recombinant "minimal" enzyme cocktail containing beta-xylosidase and novel endo-1,4-beta-xylanase and alpha-(L)arabinofuranosidase activities. Biotechnol Progr 2007, 23:100-107.

27. Shekiro J, Kuhn EM, Selig MJ, Nagle NJ, Decker SR, Elander RT: Enzymatic conversion of xylan residues from dilute acid-pretreated corn stover. Appl Biochem Biotechnol 2012, 168:421-433.

28. Kraft MJ, Keller JL, Riotto AM: Compression screw with combination single and double flights. 2008, US Pat\# 7:074-357.

29. Svedberg P: Plug screw feeder for feeding cellulose pulp/chips. US Pat\# 8 2012:181-570.

30. Wilén C, Rautalin A: Handling and feeding of biomass to pressurized reactors: Safety engineering. Bioresource Technol 1993, 46:77-85.

31. Zeitsch KJ: The Chemistry and Technology of Furfural and its Many By-Products. New York: Elsevier; 2000

32. Yancey $\mathrm{N}$, Wright $\mathrm{CT}$, Westover TL: Optimizing hammer mill performance through screen selection and hammer design. Biofuels 2013, 4:85-94.

33. Hatzis C, Riley C, Philippidis G: Detailed material balance and ethanol yield calculations for the biomass-to-ethanol conversion process. Appl Biochem Biotechnol 1996, 57-58:443-459.

34. Roche CM, Dibble CJ, Stickel JJ: Laboratory-scale method for enzymatic saccharification of lignocellulosic biomass at high-solids loadings. Biotechnol Biofuels 2009, 2:28.

35. Sluiter A, Hames B, Ruiz R, Scarlata C, Sluiter J, Templeton D, Crocker D: ; Determination of structural carbohydrates and lignin in biomass [http:// www.nrel.gov/docs/gen/fy13/42618.pdf].

36. Sluiter A, Hames B, Ruiz R, Scarlata C, Sluiter J, Templeton D: Determination of sugars, byproducts, and degradation products in liquid fraction process samples. [http://www.nrel.gov/docs/gen/fy08/42623.pdf].

doi:10.1186/1754-6834-7-23

Cite this article as: Shekiro et al:: Characterization of pilot-scale dilute acid pretreatment performance using deacetylated corn stover. Biotechnology for Biofuels 2014 7:23. 